\title{
Metode Pengukuran dan Model Pendugaan Biomassa Nypa Fruticans di Sungai Tallo, Makassar-Indonesia
}

\section{Measurement Methods and Estimate Models of Nypa Fruticanus Biomass in Tallo River, Makassar-Indonesia}

\author{
Rahman $^{1}$, Hefni Effendi ${ }^{1,2}$, Iman Rusmana ${ }^{3}$, Mukti Ali ${ }^{4 *}$ \\ ${ }^{1}$ Department of Aquatic Resources Management, Bogor Agricultural University, Bogor, Indonesia. \\ ${ }^{2}$ Center for Environmental Research, Bogor Agricultural University, Bogor, Indonesia. \\ ${ }^{3}$ Department of Biology, Bogor Agricultural University, Bogor, Indonesia. \\ ${ }^{4}$ Faculty of Fisheries, Lamongan Islamic University, Lamongan, Indonesia. \\ *Corresponding Author: muktiali.ipb@gmail.com
}

\begin{abstract}
ABSTRAK
Penelitian tentang estimasi dan model pendugaan biomassa pada tegakan pohon mangrove telah banyak dilakukan baik dalam tingkat ekosistem maupun spesies, namun belum pernah dilakukan pada spesies Nypa fruticans. Penelitian ini bertujuan untuk membuat sebuah model penduga nlilai biomassa Nypa fruticans di Sungai Tallo yang terdapat di Makassar-Indonesia yang merupakan salah satu habitat mangrove. Pendugaan biomassa dilakukan dengan menebang mangrove sebanyak 15 pohon pada range diameter terbesar hingga terkecil. Biomassa dihitung berdasarkan berat kering yang diperoleh dari pengeringan sub contoh berat basah pada suhu $130{ }^{\circ} \mathrm{C}$ selama $48 \mathrm{jam}$. Analisis model penduga biomassa menggunakan regresi linier dan model allometrik yang akan menyatakan hubungan antara diameter pangkal atau pelepah dengan nilai biomassa mangrove. Hasil analisis menunjukkan bahwa model penduga biomassa Nypa fruticansbersifat allometrik yang berkorelasi dengan diameter pangkal dan diameter pelepah yaitu $\mathrm{B}=0,098(\mathrm{DB})^{1,4934}$ dan $\mathrm{B}=0,222(\mathrm{DS})^{2,7048}$ dan lebih baik dibandingkan model analisis regresi. Total biomassa Nypa fruticans menurut diameter pangkal dan pelepah yakni 174574,4kgatau 40132, $69 \mathrm{~kg} / \mathrm{ha}$ dan 173959,4kg atau 39991, $32 \mathrm{~kg} / \mathrm{ha}$.
\end{abstract}

Kata kunci: Biomassa, Model penduga, Nypa fruticans, Tallo River.

\section{ABSTRACT}

Research on the estimation of biomass and biomass estimate model on the tree stand of mangrove trees has amply been done in the ecosystem to species levels, but to date it has never been done on the species Nypa fruticanus. This study aimed to create a model of biomass estimation of Nypa fruticanus. The Tallo River in Makassar-Indonesia is one of the mangrove's habitat, especially the Nypa fruticanus. Biomass estimation was conducted by cutting 15 mangrove trees in the largest to smallest diameters. Biomass was measured based on dry weight from the drying of wet weight subsample in $130^{\circ} \mathrm{C}$ temperature for 48 hours. The analysis of biomass estimation model utilised linear regression and allometric models. Results show that the biomass estimate model of Nypa fruticanus is allometric correlating to the base diameter of $B=0.098(D B)^{1.4934}$ and stem diameter of $B=0.222(D S)^{2.7048}$ and better compared with models of regresssion analysis. The total biomass of Nypa fruticanus based on mangrove numbers and base or stem diameters were $174574.4 \mathrm{~kg}$ or $40132.69 \mathrm{~kg} / \mathrm{ha}$ and $173959.4 \mathrm{~kg}$ or $39991.32 \mathrm{~kg} / \mathrm{ha}$.

Keywords: Biomass, Nypa fruticanus, Tallo River.

\section{PENDAHULUAN}

Pemanasan global merupakan salah satu peristiwa penting yang cukup ditakuti, bukan saja di Indonesia, tetapi juga berkembang menjadi isu global yang dibicarakan oleh hampir seluruh kalangan internasional. Kontributor terbesar pemanasan global saat ini adalah karbon dioksida dan metana yang dihasilkan dari berbagai aktivitas manusia seperti pembakaran bahan bakar fosil, kendaraan bermotor dan mesin industri yang menyebabkan gas karbon terakumulasi (IPCC, 2001).

Ekosistem mangrove memiliki fungsi ekologis yang sangat penting terutama bagi 
wilayah pesisir. Salah satu fungsi ekologis mangrove adalah mangrove sebagai penyimpan karbon. Rosot karbondioksida berhubungan erat dengan biomassa tegakan. Jumlah biomasa suatu kawasan diperoleh dari produksi dan kerapatan biomasa yang diduga dari pengukuran diameter, tinggi, berat jenis dan kepadatan setiap jenis pohon. Biomassa dan rosot karbon pada mangrove merupakan salah satu manfaat mangrove di luar potensi biofisik lainnya, dimana potensi biomassa mangrove yang besar adalah penyerap dan penyimpan karbon guna pengurangan kadar $\mathrm{CO}_{2}$ di udara. Hal ini didukung oleh Hairiah \& Rahayu (2007), dan Komiyana et al. (2008) yang menyatakan bahwa ekosistem mangrove memiliki peranan yang penting dalam mengurangi efek gas rumah kaca sebagai mitigasi perubahan iklim karena mampu mereduksi $\mathrm{CO}_{2}$ melalui mekanisme sekuestrasi, yaitu penyerapan karbon dari atmosfer dan penyimpanannya dalam bentuk biomassa.

Daniel et al. (2011) menyatakan bahwa tiap hektar ekosistem mangrove dapat menyimpan karbon empat kali lebih banyak dibanding dengan ekosistem lainnya. Hal ini sejalan dengan Siddique et al. (2012) dan Alemaheyu et al. (2014) yang menyatakan bahwa tumbuhan mangrove memiliki kemampuan yang baik dalam menyerap karbon bahkan mencapai 296 tonC/ha.

Penelitian tentang estimasi dan model penduga biomassa pada tegakan pohon mangrove telah banyak dilakukan baik dalam tingkat ekosistem maupun spesies, misalnya Clough \& Scout (1989) meneliti model penduga biomassa Rhyzophora spp, Bruguiera Gymnorhyza, Bruguiera palviflora, Ceriops australis, dan Xylocarpus granatum; Imbert \& Rollet (1989) meneliti model penduga biomassa Avicennia germinans, Laguncaria racemosa, dan Rhyzophora mangle; Fromard et al. (1998) meneliti model penduga biomassa Avicennia germinans, Laguncaria racemosa, dan Rhyzophora spp; Hilmi (2003) meneliti model penduga kandungan karbon pada spesies Rhyzophora spp dan Bruguiera spp; Ong et al. (2004) meneliti model penduga Rhyzophora apiculata; Komiyana et al. (2005) meneliti model penduga biomassa Avicennia $s p$ dan Bruguiera cylindrica; dan Siddique et al. (2012) menduga nilai biomassa Aegiliatis rotundifora.

Salah satu spesies mangrove yang banyak diabaikan dalam penelitian model penduga biomassa adalah Nypa fruticans. Nypa fruticans memiliki bentuk pohon (batang) dan pelepah yang unik seperti palem. Hal ini menyebabkan kesulitan dalam pengukuran diameter setinggi dada $(d b h=130 \mathrm{~cm})$ sehingga dalam pengukuran biomassa dan pendugaan kandungan karbon akan berbeda dengan spesies mangrove lainnya. Penelitian tentang pendugaan nilai biomassa dan kandungan karbon spesies Nypa fruticans hampir belum pernah dilakukan.

Salah satu wilayah yang merupakan habitat ekosistem mangrove khususnya spesies Nypa fruticans adalah sungai Tallo, MakassarIndonesia. Mangrove terutama spesies Nypa fruticans di kawasan ini masih tergolong padat (Beddu, 2011). Berdasarkan uraian diatas maka penelitian ini bertujuan untuk membuat model penduga nilai biomassa dan kandungan karbon pada spesies Nypa fruticans terutama yang terdapat di sungai Tallo, Makassar-Indonesia.

\section{METODE PENELITIAN}

\section{Pengukuran Kerapatan, Diameter Pangkal dan Pelepah}

Pengukuran kerapatan mangrove dilakukan menggunakan plot berukuran $10 \times 10$ $\mathrm{m}^{2}$. Sebanyak 10 plot diletakkan sejajar pada sisi kiri dan kanan sungai. Pengukuran diameter dilakukan pada 15 pohon pada kisaran diameter terbesar hingga terkecil. Pengukuran diameter pangkal dilakukan sekitar $15-20 \mathrm{~cm}$ di atas permukaan tanah. Pengukuran diameter pelepah dilakukan tepat dibagian pelepah yang berbentuk lingkaran pada semua pelepah yang terdapat dalam satu pohon ( Gambar 1). Diameter yang akan diuji dalam persamaan penduga biomassa adalah diameter pangkal atau rata-rata diameter pelepah.

\author{
Alat dan Bahan \\ 15 pohon mangrove \\ 250-400 gram fraksi pohon (akar) \\ 250-400 gram fraksi pohon (pelepah) \\ 250-400 gram fraksi pohon (daun) \\ 250-400 gram fraksi pohon (buah) \\ 1 buah Oven
}

\section{Penebangan, Pembagian dan Pengeringan Fraksi Pohon}

Penebangan pohon dimulai di bagian pangkal pada 15 pohon mangrove. Selanjutya melakukan langkah-langkah sebagai berikut: 
1. Melakukan pemisahan bagian-bagian fraksi pohon seperti pangkal termasuk akar, pelepah, daun, dan buah (NSO,2011).

2. Menimbang setiap bagian fraksi pohon (berat basah)

3. Mengambil sekitar 250-400 gram setiap bagian fraksi pohon (subcontoh berat basah)

4. Mengeringkan subcontoh berat basah dari setiap bagian fraksi pohon dengan menggunakan oven pada suhu $130{ }^{\circ} \mathrm{C}$ selama 48 jam.

5. Menimbang subcontoh berat kering dari setiap fraksi pohon.

6. Menjumlahkan berat masing-masing fraksi menjadi berat keseluruhan pohon (Sutaryo, 2009).

\section{Analisis Biomassa Total Pohon}

Nilai biomassa mangrove atau berat kering total diperoleh dari hasil perkalian berat basah total (berat seluruh bagian fraksi pohon) dengan nilai perbandingan antara subcontoh berat kering dengan subcontoh berat basah menurut persamaan (Hairiah \& Rahayu, 2007). Persamaan tersebut ditampilkan dalam persamaan (1).

\section{Analisis Model Penduga Biomassa}

Analisis yang akan digunakan dalam model persamaan penduga biomassa adalah regresi dan persamaan allometrik yang akan menyatakan hubungan antara diameter pangkal atau pelepah dengan nilai biomassa mangrove.

\section{Analisis Biomassa Total Ekosistem}

Nilai biomassa total Nypa fruticans yang terdapat di suatu kawasan ekosistem dihitung berdasarkan hasil perkalian antara biomassa pada tiap individu dengan total kerapatan mangrove sebagaimana persamaan (2). Nilai biomassa total dihitung menurut persamaan yang akan diperoleh dari model penduga regresi linier atau allometrik.

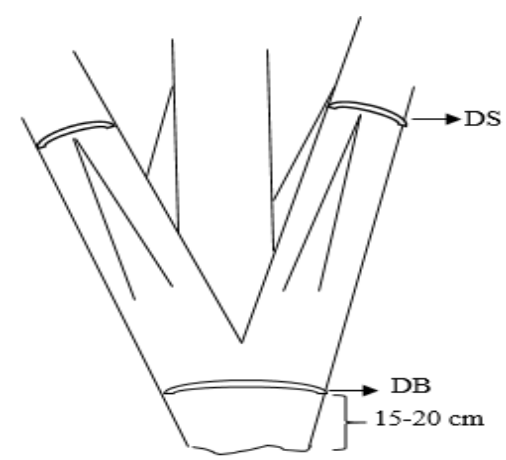

Gambar 1. Pengukuran diameter pangkal dan diameter pelepah

Berat kering $(\mathrm{kg})=\frac{\text { Subcontoh Berat Kering }(g r)}{\text { Subcontoh Berat Basah }(g r)} \times$ Berat basah $(\mathrm{kg})$

Biomassa total $(\mathrm{kg} / \mathrm{ha})=$ Biomassa $(\mathrm{kg} /$ tree $) \times$ Kerapatan $($ trees $/ \mathrm{ha})$

\section{HASIL DAN PEMBAHASAN}

\section{Biomassa Total Pohon}

Secara umum nilai biomassa setiap spesies mangrove berbeda dan dipengaruhi oleh kemampuan sekuestrasi yang dapat dianalisis berdasarkan nilai massa jenis, diameter pohon ataupun ketinggiannya. Biomassa total pohon diperoleh dari penjumlahan berat kering masingmasing fraksi pohon seperti pangkal, pelepah, daun dan buah.
Lampiran 1. menunjukkan hubungan antara diameter (pangkal dan pelepah) Nypa fruticans pada kisaran ukuran yang berbeda dengan nilai biomassa mangrove. Dari tabel tersebut juga didapatkan nilai rata-rata diameter pangkal yaitu $23,94 \mathrm{~cm}$ dan rata-rata diameter pelepah yaitu $4,00 \mathrm{~cm}$ serta berat kering (biomassa) mencapai 13,15 kg/individu. 


\section{Model Penduga Biomassa}

Hasil analisis regresi hubungan antara biomassa mangrove dengan diameter pangkal menunjukkan nilai korelasi sebesar 98,2\% dengan persamaanB $=-3,72+0,705 \mathrm{DB}$ (Gambar 2a). Korelasi biomassa terhadap diameter pelepah sebesar 95,2\% dengan persamaan B $=-14,56+6,94$ DS (Gambar 2b). Model allometrik hubungan antara diameter pangkal (DB) dan biomassa yaitu $\mathrm{B}=0,098$ (DB) ${ }^{1,4934}$ dengan $\mathrm{R}^{2}=0,991$ (Gambar 3a). Model persamaan allometrik hubungan diameter pelepah (DS) dengan biomassa adalah $\mathrm{B}=$ 0,222(DS) 2,7048 dengan $\mathrm{R}^{2}$ yaitu 0,964 (Gambar 3b).

Nilai koefisien korelasi $\left(\mathrm{R}^{2}\right)$ persamaan allometrik lebih besar dibandingkan dengan nilai $\mathrm{R}^{2}$ dari persamaan analisis regresi. Hal ini menunjukkan bahwa persamaan allometrik lebih tepat untuk menduga nilai biomassa Nypa fruticans dibandingkan dengan persamaan dari analisis regresi.

\section{Biomassa Total Ekosistem}

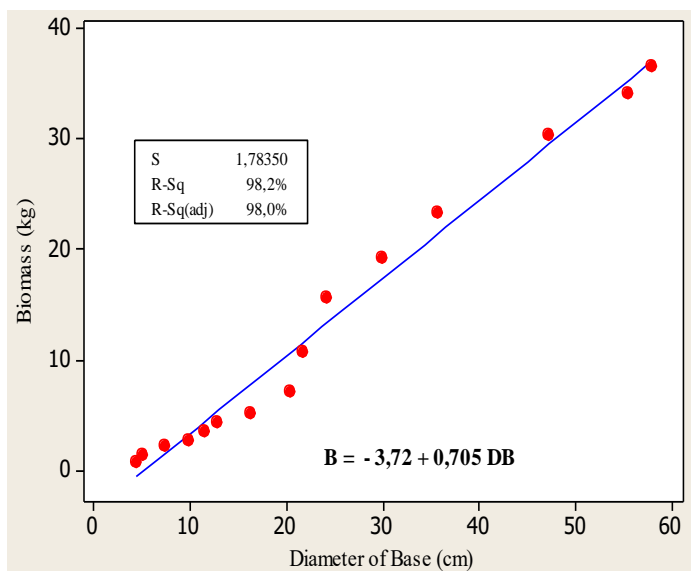

Gambar 2a. Analisis regresi hubungan antara diameter pangkal dan biomassa.

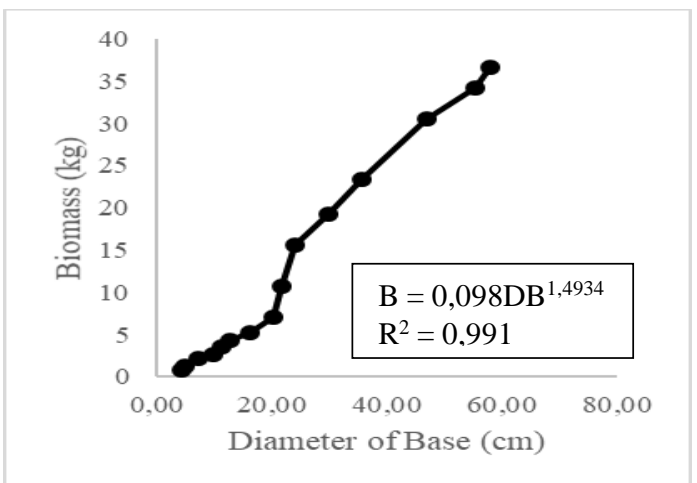

Gambar 3a: Model allometrik hubungan antara diameter pangkal dan biomassa.
Hasil pengamatan terhadap kerapatan spesies Nypa fruticans yaitu 4238 ind/ha. Biomassa total menurut model persamaan regresi berdasarkan analisis diameter pangkal yakni $242562,2 \mathrm{~kg}$ or $55762,33 \mathrm{~kg} / \mathrm{ha}$ dan lebih kecil jika dibandingkan dengan model regresi menurut diameter pelepah yakni $243342 \mathrm{~kg}$ or $55941,6 \mathrm{~kg} / \mathrm{ha}$. Biomassa total Nypa fruticans berdasarkan model allometrik diameter pangkal dan diameter pelepah cenderung sama yakni $174574,4 \mathrm{~kg}$ or $40132,69 \mathrm{~kg} / \mathrm{ha}$ and $173959,4 \mathrm{~kg}$ or $39991,32 \mathrm{~kg} / \mathrm{ha}$. Hasil analisis biomassa dengan model regresi diketahui bahwa hubungan diameter pangkal dengan biomasssa lebih besar dibandingkan dengan hubungan diameter pelepah dengan biomassa dan lebih besar pula dibandingkan hasil analisis dengan model allometrik baik menurut diameter pangkal ataupun diameter pelepah. Hasil analisis allometrik hubungan diameter pangkal dengan biomassa atau diameter pelepah dengan biomassa masih relatif sama. Hal ini menunjukkan bahwa hubungan antara diameter dengan biomassa tidaklah bersifat linier melainkan allometrik.

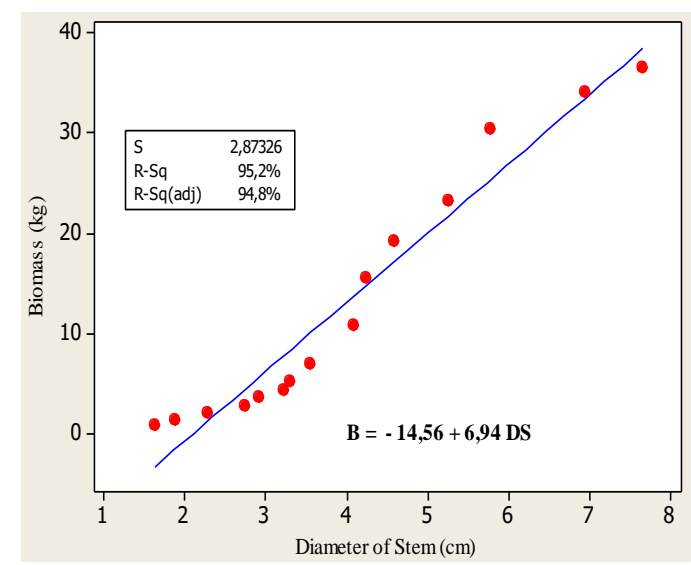

Gambar 2b. Analisis regresi hubungan antara diameter pelepah dengan biomassa.

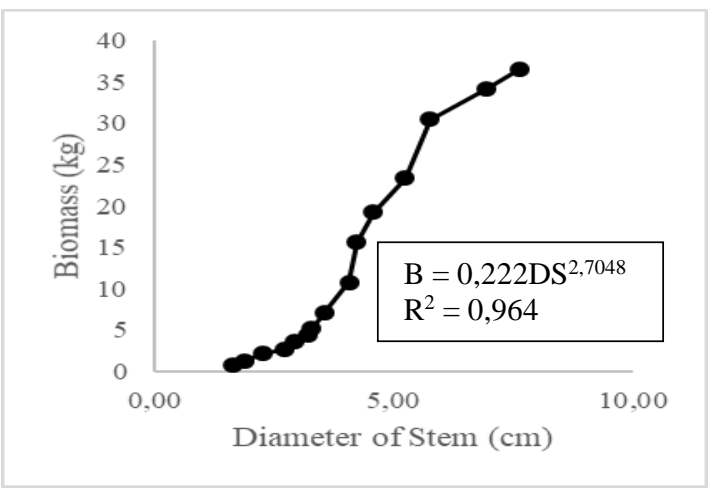

Gambar 3b: Model allometrik hubungan antara diameter pelepah dengan biomassa. 


\section{KESIMPULAN}

Model penduga biomassa Nypa fruticans berdasarkan diameter pangkal dan diameter pelepah bersifat allometrik dengan yaitu $\mathrm{B}=$ 0,098 (DB) ${ }^{1,4934}$ dengan nilai koefisien korelasi $\left(\mathrm{R}^{2}\right)=0,991$ atau $99,1 \%$ dan $\mathrm{B}=0,222(\mathrm{DS})^{2,7048}$ dengan nilai koefisien korelasi $\left(\mathrm{R}^{2}\right)$ yaitu 0,964 atau $96,4 \%$. Total biomassa Nypa fruticansyang terdapat di sungai Tallo Makassar-Indonesia yaitu 40132,69 kg/ha menurut diameter pangkalatau 39991,32 kg/ha menurut diameter pelepah.

\section{UCAPAN TERIMA KASIH}

The author would like to express the highest gratitude to the Indonesian Endowment Fund for Education (LPDP) as the main sponsor of this research so that the research could be conducted successfully.

\section{DAFTAR PUSTAKA}

Alemaheyu, F., Richard, O., James, M.K., Wasonga, O. 2014. Assesment of mangroves covers change and biomass in Mide Creek, Kenya. Open J. of Forestry, (4):398-413.

Beddu, S. 2011. Bantaran sungai sebagai konservasi lansekap alami (studi kasus: bantaran sungai Tallo Makassar). Jurnal Teknik Lingkungan, (5): 1-7.

Clough, B.F., Scott, K. 1989. Allometric relationships for estimating above-ground biomass in six mangrove species. Forest Ecology and Management, 27: 117-127.

Daniel, C., Danoto, J., Kauffman, B., Murdiyarso, D., Kurnianto, S., Stidham, M., Kannine, M. 2011. Mangroves among the most carbon-rich forests in the tropics. Nature Geoscience. doi: 10.1038/naturgeo.2011.206.

Fromard, F., Puig, H., Mougin, E., Betoulle, J.L., Cadamuro, L. 1998. Structure, above-ground biomass and dynamics of mangrove ecosystems: new data from French Guiana. Springer-Verlag, Oecologia, p 39-53.

Hairiah, K., Rahayu, S. 2007. Pengukuran Karbon Tersimpan di Berbagai Macam Penggunaan Lahan. World Agroforestry Centre. ICRAF, SEA Regional Office, Universitas Brawijaya, Indonesia. p 3-4.

Hilmi, E. 2003. Model penduga kandungan karbon pada pohon kelompok jenis Rhyzophora spp dan Bruguiera spp dalam tegakan hutan mangrove (studi kasus: di Indragiri Hilir Riau). [Disertasi], Institut Pertanian Bogor. Bogor. p115.

Imbert, D., Rollet, B. 1989. Phytomasseaerienneet production primairedans la mangrove du Grand CulDe-Sac Marin (Guadeloupe, Antillas Francaises). Bulletin D'Ecologie, 20(1): 27-39.

[IPCC] Intergovernmental Panel on Climate Change. 2001. Climate change 2001: the scientific basis. Cambridge University Press, Cambridge. 881p.

Komiyana, A., Ong, J.E., Poungparn, S. 2008. Allometry, biomass and productivity of mangrove forest: a. review. A Botany, 89:128-137.

Komiyama, A., Poungparn, S., Kato, S. 2005. Coomon allometric equation for estimating the tree weight of mangroves. Cambridge University Press. J. of Tropical Ecology. 21:471-477.

National for Standardization Organization. 2011. Ground Based Forest Carbon Accounting. Indonesian National Standard. Jakarta. $12 p$.

Ong, J.E., Gong, W.K., Wong, C.H., 2004. Allometry and partitioning of the mangrove Rhizophora apiculata. Forest Ecology and Management, 188: 395-408.

Siddique, H.R.M., Hossain, M., Chowdhury, K.R.M. 2012. Allometric relationship for estimating above-ground biomass of aegialitis rotundifolia roxb of sundarbans mangrove forest, in Bangladesh. $\mathrm{J}$ of Forestry Research, 23(1):23-28.

Sutaryo, D. 2009. Penghitungan Biomassa, Sebuah Pengantar untuk Studi Karbon dan Perdagangan Karbon. Wetlands International Indonesia Programme. Bogor, Indonesia. 48p. 


\section{Appendix 1. Berat kering beberapa bagian fraksi Nypa fruticans}

\begin{tabular}{|c|c|c|c|c|c|c|c|c|c|c|c|c|c|c|c|}
\hline \multirow[t]{2}{*}{ No } & \multicolumn{2}{|c|}{$\begin{array}{l}\text { Diameter } \\
(\mathrm{cm})\end{array}$} & \multicolumn{4}{|c|}{$\begin{array}{l}\text { Berat basah total } \\
\qquad(\mathrm{kg})\end{array}$} & \multicolumn{4}{|c|}{$\begin{array}{l}\text { Sub contoh berat basah } \\
\text { (g) }\end{array}$} & \multicolumn{4}{|c|}{$\begin{array}{l}\text { Sub contoh berat kering } \\
(\mathrm{g})\end{array}$} & \multirow{2}{*}{$\begin{array}{c}\text { Berat } \\
\text { Kering } \\
\text { Total }\end{array}$} \\
\hline & DB & DS & Akar & Pelepah & Daun & Buah & Akar & Pelepah & Daun & Buah & Akar & Pelepah & Daun & Buah & \\
\hline 1 & 57,91 & 7,65 & 17,61 & 97,81 & 16,81 & 5,02 & 300 & 500 & 400 & 400 & 76 & 122,2 & 164,02 & 105 & 36,58 \\
\hline 2 & 55,36 & 6,94 & 15,83 & 96,14 & 15,12 & 2,81 & 300 & 500 & 400 & 400 & 75,4 & 120,8 & 163,83 & 103,8 & 34,13 \\
\hline 3 & 47,09 & 5,77 & 13,24 & 89,02 & 12,37 & 2,12 & 300 & 500 & 400 & 400 & 76 & 120,67 & 164,06 & 104,16 & 30,46 \\
\hline 4 & 35,64 & 5,24 & 9,41 & 70,15 & 9,45 & 0 & 300 & 500 & 400 & 0 & 75,54 & 121,88 & 164,2 & 0 & 23,35 \\
\hline 5 & 29,91 & 4,57 & 7,21 & 62,67 & 5,28 & 0 & 300 & 500 & 400 & 0 & 75,62 & 122,04 & 163,29 & 0 & 19,27 \\
\hline 6 & 24,18 & 4,23 & 5,72 & 51,54 & 3,92 & 0 & 300 & 500 & 400 & 0 & 74,48 & 122,16 & 163,38 & 0 & 15,61 \\
\hline 7 & 21,64 & 4,07 & 5,15 & 36,23 & 1,72 & 0 & 300 & 500 & 400 & 0 & 76,12 & 120,43 & 165,05 & 0 & 10,74 \\
\hline 8 & 20,36 & 3,54 & 4,08 & 22,08 & 1,54 & 0 & 300 & 500 & 400 & 0 & 74,68 & 122,2 & 164,24 & 0 & 7,04 \\
\hline 9 & 16,23 & 3,29 & 2,98 & 16,4 & 1,02 & 0 & 300 & 500 & 400 & 0 & 76,08 & 122,12 & 164,22 & 0 & 5,18 \\
\hline 10 & 12,73 & 3,22 & 1,46 & 14,82 & 0,98 & 0 & 300 & 500 & 400 & 0 & 75,24 & 121,81 & 163,98 & 0 & 4,38 \\
\hline 11 & 11,45 & 2,91 & 1,04 & 12,26 & 0,82 & 0 & 300 & 500 & 400 & 0 & 75,06 & 122,02 & 163,76 & 0 & 3,59 \\
\hline 12 & 9,86 & 2,73 & 0,86 & 9,06 & 0,69 & 0 & 300 & 500 & 400 & 0 & 75,18 & 120,89 & 164,14 & 0 & 2,69 \\
\hline 13 & 7,32 & 2,28 & 0,72 & 7,15 & 0,53 & 0 & 300 & 500 & 400 & 0 & 74,83 & 122,22 & 164 & 0 & 2,14 \\
\hline 14 & 5,09 & 1,88 & 0,52 & 4,21 & 0,41 & 0 & 300 & 500 & 400 & 0 & 74,86 & 121,24 & 164,2 & 0 & 1,32 \\
\hline 15 & 4,39 & 1,62 & 0,38 & 2,04 & 0,36 & 0 & 300 & 500 & 400 & 0 & 75,38 & 122,25 & 164,12 & 0 & 0,74 \\
\hline Average & 23,94 & 4,00 & 5,75 & 39,44 & 4,73 & 0,66 & 300 & 500 & 400 & 80 & 75,36 & 121,66 & 164,03 & 20,86 & 13,15 \\
\hline
\end{tabular}

Legend: $\mathrm{DB}=$ Diameter of Base, $\mathrm{DS}=$ Diameter of Stem 